\title{
A Antropologia na CONTEMPORANEIDADE
}

\author{
RACHEL ROCHA DE ALMEIDA BARROS ${ }^{1}$ \\ ANTONIO MOTTA ${ }^{2}$
}

À primeira vista, o título Cidades Comparadas pode sugerir ao leitor discussões relacionadas tão somente à antropologia urbana ou antropologia (da) na cidade. Mas o propósito deste dossiê vai além desse campo heurístico. No contexto aqui apresentado, o tema das cidades não constitui um fim em si mesmo, mas um ponto de partida reflexivo e de mediação empírica para o entendimento de fenômenos sociais mais amplos, produzidos em contextos urbanos, no mundo contemporâneo.

Desde o final da segunda metade do século passado, não é novidade, a antropologia vem repensando e ampliando seu objeto de investigação e, como desafio, tem abraçado o contemporâneo, articulando-o a temporalidades distintas, como perspectiva a ser encampada na pesquisa. Certamente, uma das características que tem marcado a antropologia a partir da década de 1980, sobretudo, é a superação, cada vez mais, de uma concepção estrutural da vida social para uma perspectiva em que os sujeitos, em sua diversidade social e não apenas étnica, têm se tornado produtores do social e protagonistas de mudanças na cena política.

A proposta desse dossiê vai nesta direção. Os dez artigos e três ensaios fotográficos aqui reunidos versam sobre temas distintos envolvendo a vida social de indivíduos e de grupos inseridos em dinâmicas urbanas contextualizadas, porém pautados por temporalidades diversas que refletem processos de globalização, a exemplo de fluxos e trânsitos culturais. Isso nos ajuda a problematizar a ideia de cultura não mais como algo fixo a um lugar ou a uma determinada experiência ou referência geográfica localizada, mas a partir de formas dinâmicas e processuais.

Com os efeitos da chamada "compressão tempo-espaço", as grandes distâncias se encurtaram, alguns limites ou "fronteiras físicas" que demarcavam territórios e espaços urbanos diminuíram ou até mesmo desapareceram. Deste modo, a correlação que havia entre espaço como unidade simbólica estável (baseada em relações sociais e culturais enraizadas) e seu equivalente territorial, que the conferia materialidade, parece irrelevante

\footnotetext{
${ }^{1}$ Professora do Programa de Pós Graduação em Antropologia Social da Universidade Federal de Alagoas.
}

${ }^{2}$ Pograma de Pós graduação em antropologia da UFPE (Laboratório de Estudos Avançados de Cultura Contemporânea - LEC). 
no chamado mundo globalizado. É assim que as culturas se transformaram, incorporaram e recriaram valores e sentidos, buscando um diálogo recíproco entre o local e o cosmopolita, entre o fixo e os fluxos.

Em decorrência desses processos, o mundo certamente tornou-se mais próximo porque, em larga medida, se virtualizou. O papel do imaterial e dos serviços ligados à produção desse intangível é uma das características mais evidentes do mundo contemporâneo, marcado pela intangibilidade da economia, pelos novos fluxos de capitais e de bens produzidos pela economia de mercado. Isto tem impactado diretamente as relações sociais, concorrendo para a produção de novas experiências e subjetividades, bem como novas formas de comunicação, de trabalho e de conhecimento.

Em sua maioria, os artigos aqui reunidos tangenciam alguns desses temas, tendo como fio condutor a perspectiva comparativa, o que demonstra a atualidade metodológica de um viés que estabeleceu suas bases sólidas na antropologia e permite estabelecer nexos interessantes para se pensar o rico arcabouço que o exercício da comparação - tão caro à prática dessa disciplina - pode ainda hoje nos proporcionar. Vinculada à própria gênese da antropologia, a comparação sofreu grandes e importantes transformações nas suas formas de percepção e de prática, mobilizando, ao longo da história da disciplina e a partir de diferentes orientações teórico-metodológicas, dezenas de autores clássicos que empreenderam esforços para delimitá-la, ora apontando-a como a razão maior de ser da própria antropologia, ora como exercício inerente ao ambicioso projeto desse campo disciplinar. Nessa breve apresentação, seria desnecessário e exaustivo para o leitor mencionarmos uma lista de exemplos, bastando para isso sintetizar nas palavras de Ingold $(2015)^{3}$ que, sendo o empreendimento antropológico essencialmente comparativo, devemos ter em mente que o que se compara não são objetos limitados ou entidades, mas, sobretudo, modos de ser ou de estar no mundo.

A sequência dos artigos proposta pelos organizadores busca manter uma linha que parte de ambientes e contextos mais generalizados, tais como os desdobramentos proporcionados pela internet e suas conexões com novas formas de capitalismo; o consumo de produto sem grandes centros urbanos ou a problemática do descarte do lixo. Em seguida, apresentamos reflexões a partir de contextos mais localizados, que podendo envolver o exercício comparativo tomam, para tanto, temas variados tais como patrimônio; formas de sociabilidade urbana ou iniciativas governamentais em cenários nacionais e internacionais envolvendo diferentes escalas, países, cidades ou bairros específicos. Essas reflexões podem ainda se converter em rico exercício demonstrativo de como abordar a problemática na

\footnotetext{
${ }^{3}$ INGOLD, Tim. Estar Vivo: ensaios sobre movimento, conhecimento e descrição. Coleção Antropologia. Petrópolis: Vozes, 2015.
} 
cidade apresentando, para tanto, as implicações pedagógicas de uma metodologia visual e urbana.

Nessa linha de raciocínio, O preço da palavra: a hegemonia do capitalismo eletrônicoinformático e o googleismo, de Gustavo Lins Ribeiro, se propõe a traçar um panorama analítico das sociedades pós-industriais e do poder da informação no contexto do chamado capitalismo cognitivo. Apresentando a hegemonia de um sistema industrial e econômico centrado na internet, o artigo conduz o leitor a perceber que o capitalismo eletrônicoinformático cria sua própria mercadoria. Quando se pesquisa uma palavra no Google, por exemplo, o resultado já aparece economicamente estruturado, com uma ordem hierárquica leiloada onde os licitantes compram prioridade e visibilidade. Estamos no reino das palavras mercadorias, desmaterializadas, onde o preço é desencarnado; as palavras tornam-se fetiches, adquirem um preço com a hiteconomy e a likeeconomy incrementando o mercado e transformando os consumidores em linha de produção virtual global.

Examinando os anúncios de duas marcas de cerveja com atuação no mercado nacional, o artigo Um brinde ao Diderot: cultura, imaginário urbano e publicidades de cerveja conduz o leitor à compreensão de lógicas de apropriação distintas. Valendo-se de elementos da cultura brasileira e do imaginário carioca, no primeiro caso, e de um universo impessoal e cosmopolita no segundo, Marina Frid e William Corbo apresentam, numa perspectiva comparativa, maneiras como a publicidade constrói representações do consumo da bebida através de vinculações das marcas de cerveja com as chamadas "unidades Diderot", isto é, tratando o consumo como sistema simbólico que conjuga temas, espaços, experiências e objetos presentes na cultura e apontando para o caráter complementar e comunicacional dos bens.

Apoiando-se em dois documentários e tomando o lixo como objeto de reflexão, o artigo Notas sobre as formas de apropriação dos resíduos sólidos urbanos: pensando a partir dos documentários Boca de Lixo e Lixo Extraordinário coloca em evidência as figuras do catador de resíduos e do artista plástico, cujo ponto em comum é o fato de ambos ressignificarem restos das sociedades consumistas em materiais dotados, respectivamente, de valor de uso e de valor artístico. O leitor tem a oportunidade de refletir, a partir do aporte comparativo proposto por Welkson Pires, sobre a reciclagem de dejetos em contextos de sobrevivência e de pobreza extrema por um lado, e da criação artística por outro, de que forma objetos tornados refugos pela ação do descarte prestam-se a construções subjetivas distintas.

No artigo Dinámica de un organismo nacional de patrimonio; continuidades y rupturas em vinculación com procesos histórico-sociopolíticos, Mónica Rotman apresenta um quadro comparativo que nos permite acompanhar as mudanças e transformações das políticas levadas a efeito pela Comissão Nacional de Museus, Monumentos e Lugares Históricos da Argentina, apresentando ao leitor as dinâmicas internas desse organismo estatal e suas 
características em momentos históricos distintos, sempre amparada em sua análise na contextualização temporal dessas ações com as complexas condições sociopolíticas daquele país.

Seguindo o argumento patrimonial, em Nos tempos dos charutos prateados: ressonâncias em torno do reconhecimento do Campo do Jiquiá como patrimônio histórico do Recife, Rafael Rodrigues e Roberta Mélo propõem refletir sobre diferentes ressonâncias promovidas a partir de apropriações de uma mesma área reconhecida como patrimônio histórico. Os autores oferecem ao leitor, a partir de diferentes contextos e temporalidades: 1983 - ano do tombamento, e 2009 - momento de instalação de um projeto de requalificação, a possibilidade de uma abordagem comparativa para diferentes expressões de ressonância: uma afetiva, diretamente ligada ao reconhecimento do local como patrimônio histórico da cidade, e outra instrumental, associada aos projetos de requalificação da área e aos benefícios que a ação aporta em termos de infraestrutura urbana para bairros do entorno.

Em Espaços não edificados nas concessões agudá: jardim ornamental, pomar e horta, Alexis Adandé estabelece comparação entre os jardins brasileiros e os jardins agudá, no Benin, buscando suas correlações e chamando a atenção de gestores do patrimônio para ações necessárias. Conhecidos como os brasileiros "retornados" à África ou os "brasileiros do Benin", os agudás, em seu movimento de retorno no fim do período escravagista brasileiro, ou durante os séculos de escravidão (por meio de alforrias), transportaram uma série de referências para o Benin, entre elas plantas presentes no cotidiano brasileiro (fruteiras, hortaliças, flores), além de concepções que nortearam a construção desses espaços. Dando relevo a aspectos da diáspora africana no novo mundo, o artigo demonstra as trocas culturais estabelecidas entre o Brasil e partes do continente africano.

Partindo da ideia de cidade como obra, e da continuidade do rural no urbano, o artigo Quadrilha junina e cidade, mercado e beleza da obra chama a atenção do leitor para a centralidade do universo rural que se mantém vivo na cidade através de uma memória da migração que engloba imagens e símbolos do universo rural. Os protagonistas da quadrilha junina, em ambiente citadino, participam crítica e conscientemente da festa, estabelecendo diálogos com as políticas de cultura, com a dimensão que o espetáculo alcança e com a crescente presença da mídia. Nesses termos, Luciana Chianca apresenta a ressignificação da quadrilha em novo ambiente e momento, possibilitando ao leitor a percepção das redes que se estruturam em torno da atividade que arregimenta profissionais de diferentes campos e arrebanha apoios de diferentes naturezas para garantir o brilho da festa.

Tomando uma parte do cenário urbano de Imperatriz, MA como reflexão, Glamour e precarização na Praça Tiradentes: metáforas, temporalidade e narrativas de um logradouro público busca aproximar a antropologia da noção de metáfora para analisar as narrativas de 
atores sociais que participam da dinâmica daquele espaço. O aporte comparativo proposto por Jesus Pereira e Ana Paula Pereira acontece a partir de dimensões temporais distintas e da construção metafórica presentes nos discursos que versam sobre a praça. Articulando elementos do presente e do passado, o leitor é conduzido ao ambiente, entendendo-o como um campo de tensões e de intersecções de diferentes experiências. O fio condutor centra-se na análise de registros narrativos e nas metáforas que subsidiam a reflexão sobre temporalidades distintas e relações sociais naquele logradouro público.

O artigo de Dorothée Sy, Representações Compartilhadas sobre o Programa Minha Casa, Minha Vida: análise do discurso sobre a construção do novo tempo na cidade de Lajeado, propõe desvendar o discurso mítico e a mensagem oculta existentes por trás da fabricação do "sonho da casa própria" e que são articulados pelas políticas do governo municipal de uma cidade gaúcha. Amparando-se em autores que discutem o Estado e a produção do discurso, oferece ao leitor uma análise através de imagens divulgadas pela imprensa e por imagens publicitárias institucionais.

Fechando o conjunto de artigos, Antropologia com Imagens: Cartas aos narradores urbanos e o Livro do etnógrafo relata experiências de ensino em antropologia visual e da imagem e em antropologia urbana no curso de graduação em Ciências Sociais e no PPGAS da UFRGS desenvolvidas pelo Núcleo de Antropologia Visual (Navisual) e pelo Banco de Imagens e Efeitos Visuais (BIEV), dando realce a dois projetos - a exposição Carta aos Narradores Urbanos: etnografia de rua na Porto Alegre das intervenções artísticas e Livro do Etnógrafo. Com destaque à produção do conhecimento, Ana Luiza da Rocha, Cornelia Eckert, Mariana Barbosa e Matheus Cervo propõem uma ruptura na linearidade da linguagem escrita ao tempo em que apresentam o hipertexto como possibilidade para múltiplas leituras do material etnográfico possibilitando que o leitor-navegador seja ele também agente da construção interpretativa.

Além dos artigos, o dossiê apresenta também ao leitor três ensaios visuais. O ensaio Currais da Memória: o tempo de saber fazer, da antropóloga Amanda Régia Amorim Morais dos Santos, resultado de sua pesquisa de mestrado sobre o processo de gentrificação de um bairro de pescadores em Maceió-AL, mostra o impacto desse processo sobre a pesca artesanal que perde espaço para a ocupação urbana desordenada e compromete a continuidade do ofício tradicional da pesca de curral.

O ensaio Benigno Benin - Missão Cultural Maceió-Benin 2018, do artista visual Francisco Oiticica Filho, traz imagens que dialogam com o sentimento experimentado pelo fotógrafo com aquele país. As ruas, o estilo de vida, a religiosidade, momentos de trabalho, são aspectos retratados pelas lentes desse fotógrafo que, sob o impacto da alteridade africana, nos oferece uma mostra da estética, da alegria e da receptividade presentes naquele país. 
Por fim, o ensaio do antropólogo Fabrício Barreto, Bem-vindo ao Porto: graffiti na paisagem da região portuária da cidade de Pelotas/RS, também fruto de sua dissertação de mestrado em antropologia, apresenta fotografias de graffitis existentes naquele bairro portuário que antes habitado por operários passa, a partir da reestruturação da Universidade Federal de Pelotas, a abrigar novos espaços acadêmicos e a ser buscado como residência por estudantes. Retratando a condição de impermanência da cidade, os graffitis mostram seu potencial transformador, apresentando o bairro como uma galeria a céu aberto.

A capacidade de percepção e modos de olhar dos autores e autoras reunidos neste dossiê temático permitiram-lhes perscrutar um campo multifacetado de interesses temáticos, reunindo diferentes tipos de experiências desenvolvidas em contextos urbanos e tendo como desafio maior uma antropologia na contemporaneidade. 